\title{
Modeling disturbance-based native invasive species control and its implications for management
}

\author{
Nancy Shackelford, ${ }^{1,5}$ Michael Renton, ${ }^{1,2,3,4}$ Michael P. Perring, ${ }^{1}$ and Richard J. Hobbs ${ }^{1}$ \\ ${ }^{1}$ School of Plant Biology, University of Western Australia (M090), 35 Stirling Highway, Crawley, WA 6009 Australia \\ ${ }^{2}$ Centre of Excellence for Climate Change, Forest and Woodland Health, Murdoch University, Murdoch, WA 6150 Australia \\ ${ }^{3}$ CSIRO Ecosystem Sciences, Floreat, WA 6014 Australia \\ ${ }^{4}$ Plant Biosecurity Cooperative Research Centre, LP.O. Box 5012, Bruce ACT 2617 Australia
}

\begin{abstract}
Shifts in disturbance regime have often been linked to invasion in systems by native and nonnative species. This process can have negative effects on biodiversity and ecosystem function. Degradation may be ameliorated by the reinstatement of the disturbance regimes, such as the reintroduction of fire in pyrogenic systems. Modeling is one method through which potential outcomes of different regimes can be investigated. We created a population model to examine the control of a native invasive that is expanding and increasing in abundance due to suppressed fire. Our model, parameterized with field data from a case study of the tree Allocasuarina huegeliana in Australian sandplain heath, simulated different fire return intervals with and without the additional management effort of mechanical removal of the native invader. Population behavior under the different management options was assessed, and general estimates of potential biodiversity impacts were compared. We found that changes in fire return intervals made no significant difference in the increase and spread of the population. However, decreased fire return intervals did lower densities reached in the simulated heath patch as well as the estimated maximum biodiversity impacts. When simulating both mechanical removal and fire, we found that the effects of removal depended on the return intervals and the strategy used. Increase rates were not significantly affected by any removal strategy. However, we found that removal, particularly over the whole patch rather than focusing on satellite populations, could decrease average and maximum densities reached and thus decrease the predicted biodiversity impacts. Our simulation model shows that disturbance-based management has the potential to control native invasion in cases where shifted disturbance is the likely driver of the invasion. The increased knowledge gained through the modeling methods outlined can inform management decisions in fire regime planning that takes into consideration control of an invasive species. Although particularly applicable to native invasives, when properly informed by empirical knowledge these techniques can be expanded to management of invasion by nonnative species, either by restoring historic disturbance regimes or by instating novel regimes in innovative ways.
\end{abstract}

Key words: adaptive management; Allocasuarina huegeliana; fire; individual-based model; intermediate disturbance; kwongan; native encroachment; native invasive species; rock sheoak; sandplain heathland; Western Australia.

\section{INTRODUCTION}

Invasive species have been shown to negatively impact biodiversity levels and ecosystem function through direct effects of competition, mutualism, or predation, as well as indirect effects such as changes to microclimate, disturbance regimes, and nutrient cycling (Vitousek et al. 1996, Mack and D'Antonio 1998, Parker et al. 1999). Although the term invasion is most often applied to nonnatives, similar indirect and direct effects can be seen in the spread of some species within their own native range (Valéry et al. 2008, Davis 2009). Humaninduced changes in environmental conditions can cause

Manuscript received 29 October 2012; revised 1 March 2013; accepted 1 March 2013. Corresponding Editor: R. A. Hufbauer.

${ }^{5}$ E-mail: nancy.shackelford@gmail.com higher establishment and survivorship or increased per capita impact by a native species. This can lead to environmental and economic harm and elevate a native species to invasive status (Carey et al. 2012). Invasions by native species can represent major shifts in composition and species structure, such as invasion by woody species in North American grasslands (Van Auken 2009).

The causes of native species invasion are not fully understood. However, as shown repeatedly in observational and experimental studies, disturbance is often a precursor to biological invasion (Hobbs and Huenneke 1992, Hierro et al. 2006). The link between disturbance and invasion is intuitively strong in the case of native invaders because other factors commonly invoked to explain invasion by alien species, such as enemy release, pathogen avoidance, or new mutualistic associations 
(Pyšek and Richardson 2010), do not usually apply. Instead, native species generally become invasive due to a change in the overall system, such as in humanmediated disturbance (Simberloff et al. 2011). For example, the alteration of historic disturbance regimes, or new disturbances such as ungulate grazing, can act to shift resources in such a way as to allow previously rare species to increase rapidly in abundance and distribution. Examples include hay-scented fern (Dennstaedtia punctilobula) in New England, which has been shown to become invasive under altered grazing and thinning regimes, spreading to create dense understories that restrict seedling germination of tree species (de la Cretaz and Kelty 1999); broom snakeweed (Gutierezzia sarothrae), which can increase to become a monoculture following overgrazing or fire and is cited as one of the most undesirable weeds in its native range in the western North American rangelands (Ralphs 2011); and creosote bush (Larrea tridentate) in the Chihuahuan Desert, which has been shown to preferentially establish in areas of overgrazing and subsequently outcompete perennial grasses and forbs (Whitford et al. 2001).

The causes of invasion often suggest appropriate management strategies. To control a native invasion, treating the underlying cause of the invasion can sometimes manage the species itself (Hobbs 2000). Thus, returning a system to historical disturbance regimes, or implementing well-planned novel regimes in the face of environmental change, can be used in conjunction with more targeted species management such as manual removal to control populations of native invaders. However, utilizing disturbance as a management tool requires ecological knowledge about a system that is generally not available. Disturbance regimes are often at multiple scales, both spatially and temporally, and gathering comprehensive experimental and observational data over more than a single scale can be challenging. In particular, historical observations are often poorly documented and replicated long-term experiments of large-scale disturbance events are rare. There are exceptions, however, such as the Coweeta Long Term Ecological Research (LTER) project and accompanying publications (available online). ${ }^{6}$

To date, the lack of information has prevented the widespread use of disturbance as a management strategy. Here, we explore the utility of simulation modeling to inform the disturbance-based management of native invasives by using it to understand and predict disturbance impacts on a case study population. In addition, the approach allows us to assess the effects of multiple management scenarios. This is not a new technique in exploring disturbance-based invasion control; there are many examples of fire regime modeling and its impacts on invasive species populations (e.g., Higgins and Richardson 1998, Higgins et al. 2000,

${ }^{6}$ http://coweeta.uga.edu
Pausas et al. 2006). However, application to native invasive species tends to be limited to understanding how the disturbance regime shifts have led to the invasion rather than how the disturbance may be used as a control measure (e.g., Fuhlendorf et al. 1996).

We created a spatially explicit stochastic model parameterized using empirical field data from our case study species: a native invasive tree (Allocasuarina huegeliana L.A.S. Johnson) spreading into highly diverse Australian sandplain heath. An altered fire regime over the last century has been implicated in the observed spread of $A$. huegeliana into the heath, an invasion that probably is resulting in diversity declines and eventual loss of entire heath patches (Beecham et al. 2009). Unlike relying solely on experimental and observational data, a modeling methodology allowed us to assess management impacts over century-long time scales, a necessary trait when disturbance in the system occurs only once every $40-70$ years. Our broad aim was to examine ways in which management decisions concerning the use of disturbance regimes to maintain conservation goals could be informed through modeling techniques. This endeavor is illustrated with a particular system, but we are mindful of the need to be sufficiently general as to be of wider use and interest: as such, our model easily could be modified to represent other species of interest in alternative systems. Specifically, we focused on two key management questions. (1) How does the return interval or regularity of fire regime affect the abundance of Allocasuarina huegeliana and its spread into heath patches? (2) How does mechanical removal in coordination with fire regime alter the abundance of Allocasuarina huegeliana, its spread into heath patches, and its estimated impacts on biodiversity?

\section{Methods}

We focus on concerns about invasion by the native species Allocasuarina huegeliana, a fire-sensitive tree species that in the last several decades has been invading in sandplain heath (kwongan) habitat where previously it was recorded as rare or absent (Main 1993, Bamford 1995). The species is of particular interest because there is increasing concern that invasion by A. huegeliana is causing a decrease in kwongan biodiversity through canopy closure, micro-environmental change, and competition. Consequently, management organizations such as the Department of Environment and Conservation (DEC) have established site-specific adaptive management plans incorporating the control of A. huegeliana spread for the preservation of alpha (within-site) species diversity (Beecham et al. 2009). However, there is currently limited understanding of how to achieve that control with minimal interference in the native system. We developed an individual-based model of A. huegeliana populations to examine the efficacy of a number of single and combined management options, with a focus on fire as the predominant method of control. Our goal was to predict how differing fire regimes, and the pairing 
of fire with mechanical removal, affect $A$. huegeliana spread in kwongan.

\section{The native invader}

Allocasuarina huegeliana (rock sheoak) is a dioecious tree species native to Western Australia. Although it creates a relatively open canopy, its pine-like needles shed heavily, resulting in a thick litter layer in the understory with little light penetration to the ground surface. The seed is morphologically adapted to wind dispersal, thought to be its primary mechanism of dispersal. As a reseeder species, A. huegeliana germinates in large numbers after fire (Yates et al. 2003). However, postfire seedling mortality can be high under the postfire conditions, which include harsh microclimatic conditions and preferential grazing by native herbivores (Maher et al. 2010).

\section{Kwongan study system}

Kwongan is a highly diverse shrub-dominated ecosystem found predominantly in the wheatbelt region of Western Australia (Pate and Beard 1984); it resembles the fynbos of South Africa and the chaparral of the southwestern United States. It is composed mainly of woody cover $<2 \mathrm{~m}$ tall, a feature that can be attributed to the low moisture and nutrient levels of the sandy soils commonly associated with the kwongan (Pate and Beard 1984). Vegetation in the kwongan is adapted to frequent fires that can occur from early spring (September) through late autumn (May), with many life history stages being dependent on fire for optimal occurrence (Keith et al. 2007). Fire also maintains high species diversity among canopy layers, opening large portions of the canopy after fire and facilitating recruitment and growth in the understory (Keith et al. 2002).

Our case study focuses on $A$. huegeliana invasion in Tutanning Nature Reserve, a 2140-ha reserve located $\sim 150 \mathrm{~km}$ southeast of Perth, Western Australia. The site presents an ideal opportunity to look at the impacts of disturbance regime shifts in an otherwise relatively intact system. Although surrounded by agriculture, the reserve is under protection and management by DEC, experiences low human traffic, and contains few exotic invasive species. Fragmentation and land use change probably have caused the fire frequency in the region to decline (Prober and Smith 2009). Prescribed fires (fires that are deliberately lit and carefully controlled by DEC) occur infrequently. Parameterization was largely drawn from existing data on A. huegeliana behavior in Tutanning and other wheatbelt remnants. Maher (2007) conducted a series of studies across three remnants including Tutanning. She investigated $A$. huegeliana population structure and conducted experimental plantings of $A$. huegeliana seeds and seedlings to study establishment and survival under a range of environmental conditions. We drew heavily on her results as well as on another study of seed dispersal in the wheatbelt through pan traps (Standish et al. 2007) and on expert opinion of scientists at the regional- and statelevel DEC offices. Additionally, we conducted our own population surveys of $A$. huegeliana in Tutanning (N. Shackelford and M. P. Perring, unpublished data) to inform parameters such as female probability.

\section{Model structure}

The A. huegeliana population model was coded in $\mathrm{R}$ ( $\mathrm{R}$ Development Core Team 2009) and is an individualbased matrix model (see Table 1 for complete list of parameters). A single cell has three possible states: absence of $A$. huegeliana, presence of $A$. huegeliana seedling, or presence of $A$. huegeliana adult individual. The seedling state allows only one seedling per cell; multiple seedlings were considered to ultimately compete down to a single individual, so mortality was assumed for each seedling after the first. Each cell is a square with length $2.25 \mathrm{~m}$, approximating the density of a monoculture stand (N. Shackelford, personal observation). For a more detailed description of the determination of each parameter, please see Table 1 and Shackelford et al. (2011). Time steps are annual and include seed production, establishment, aging, and death (Fig. 1). A. huegeliana is dioecious, and we designated $40 \%$ of the population as seed-producing females. Thus, seeds produced each year had a $40 \%$ chance of being female and a $60 \%$ chance of being male. Once of reproductive age, each female trees produces a number of seeds each year, $s_{t}$, all assumed to germinate immediately if they land in an empty cell. The value of $s_{t}$ does not vary between individuals within a year (all females will produce the same number of seeds in a given year), but stochastically varies between years due to seasonal effects and based on fire occurrence. Few data exist on Allocasuarina seed production, so we calibrated $s_{t}$ based on field-collected density data (Maher 2007). We ran the model for 70 years without fire over a range of values for $s_{t}$, choosing the value most reasonable and most consistent with the field findings.

Newly produced seeds are distributed throughout the landscape using a dispersal distance drawn randomly from a Cauchy distribution with location $x_{0}=0$ and scale $\gamma=1.25$ to simulate a seed rain in which $98 \%$ of the seed falls within 20 cells [45 m] of the parent tree (Standish et al. 2007). The direction of dispersal is randomly drawn from a uniform distribution from 0 to $2 \pi$. Seedlings are more vulnerable to mortality than are fully established adults. Therefore, a high rate of individual mortality is assumed for the first two years, at which point any surviving seedling becomes an adult, although reproductive maturity is not reached until later in the life cycle. A mortality probability of $5 \%$ per year is assumed for adults, whether reproductive or not, and irrespective of environmental conditions.

All species experience "good" and "bad" years in relation to the environmental conditions that determine the survival and growth of their populations. To simulate this stochasticity, our model randomly assigns 
TABle 1. Parameters used in the model for Allocasuarina huegeliana, their values, and literature sources.

\begin{tabular}{|c|c|c|c|c|}
\hline Parameter & Definition & Notes & Value & Source \\
\hline \multicolumn{5}{|c|}{ General parameters } \\
\hline$F$ & female probability & $\begin{array}{l}\text { probability that new seed } \\
\text { will be female }\end{array}$ & 0.4 & $\begin{array}{l}\text { population surveys: } \\
\text { Maher (2007); N. } \\
\text { Shackelford and M. P. } \\
\text { Perring (unpublished } \\
\text { data) }\end{array}$ \\
\hline$R$ & $\begin{array}{l}\text { minimum reproductive } \\
\text { age }\end{array}$ & $\begin{array}{l}\text { reproductive maturity } \\
\text { only occurs in years } \\
\text { where } y_{t}>0.5\end{array}$ & 9 & $\begin{array}{l}\text { postfire surveys: Yates et } \\
\text { al. (2003) }\end{array}$ \\
\hline$X_{0}$ & $\begin{array}{l}\text { Cauchy parameter: } \\
\text { location }\end{array}$ & & 0 & $\begin{array}{l}\text { measured seed dispersal: } \\
\text { Maher (2007), Standish } \\
\text { et al. (2007) }\end{array}$ \\
\hline$\Gamma$ & Cauchy parameter: scale & & 1.25 & $\begin{array}{l}\text { measured seed dispersal: } \\
\text { Maher (2007), Standish } \\
\text { et al. (2007) }\end{array}$ \\
\hline$D$ & adult mortality & & 0.05 & \\
\hline \multicolumn{5}{|c|}{ Stochastic parameters } \\
\hline$y_{t}$ & seasonal suitability & $\begin{array}{l}\text { found at start of each } \\
\text { time step; truncated } \\
\text { normal distribution }\end{array}$ & $\mu=0.5, \sigma=0.1$ & \\
\hline$d_{t}$ & seedling mortality & $\begin{array}{l}\text { truncated normal } \\
\quad \text { distribution: } d_{t}= \\
q\left(1-y_{t}, \mu, \sigma\right) \dagger\end{array}$ & $\mu=0.82, \sigma=0.06$ & field trials: Maher (2007) \\
\hline$d_{t, \mathrm{f}}$ & $\begin{array}{l}\text { seedling mortality: } \\
\text { postfire }\end{array}$ & $\begin{array}{l}\text { truncated normal } \\
\quad \text { distribution: } d_{t, \mathrm{f}}= \\
q\left(1-y_{t}, \mu, \sigma\right) \dagger\end{array}$ & $\mu=0.97, \sigma=0.01$ & $\begin{array}{l}\text { postfire surveys and field } \\
\text { trials: Yates et al. } \\
(2003) \text {, Maher (2007) }\end{array}$ \\
\hline$s_{t}$ & $\begin{array}{l}\text { viable seed production } \\
\text { per tree }\end{array}$ & $\begin{array}{l}\text { normal distribution: } s_{t}= \\
\qquad q\left(y_{t}, \mu, \sigma\right) \dagger\end{array}$ & $\mu=150, \sigma=30$ & $\begin{array}{l}\text { calibration to population } \\
\text { surveys: Maher (2007) }\end{array}$ \\
\hline \multicolumn{5}{|c|}{ Management parameters } \\
\hline$D_{\mathrm{f}}$ & adult mortality: fire & & 1.0 & $\begin{array}{l}\text { C. J. Yates (personal } \\
\text { communication) }\end{array}$ \\
\hline$D_{\mathrm{r}}$ & $\begin{array}{l}\text { adult mortality: managed } \\
\text { removal }\end{array}$ & & 0.9 & \\
\hline
\end{tabular}

$\dagger$ The quantile function $q\left(1-y_{t}, \mu, \sigma\right)$ as described in Methods: Model structure.

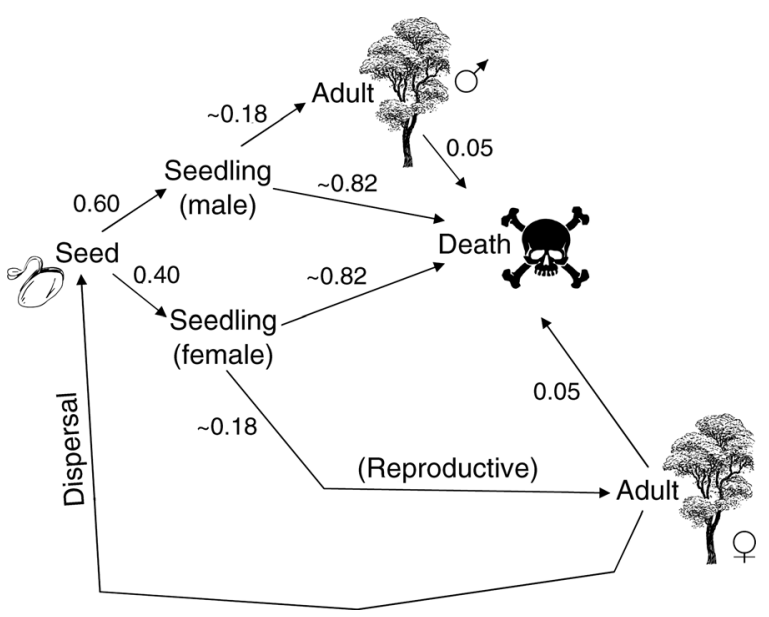

FIG. 1. Life stages of the native invasive tree Allocasuarina huegeliana in Western Australia, including proportions of individuals in each stage moving to the next. Female adults do not begin producing seed until they are a minimum of nine years old. Values preceded with " " are proportions that change annually dependent upon the stochastic seasonal suitability variable (see Methods: Model structure). an annual seasonal suitability variable, $y_{t}$. This variable ranges over a normal distribution from zero to one, with zero representing the extreme of bad years and one the extreme of good years. In any case, where the generated value is less than zero or greater than one, it is "truncated"; that is, set to zero or one, respectively. The values of three parameters vary from year to year, dependent upon $y_{t}$ : seedling mortality, seed production, and age at which the tree first reproduces (Table 1). Values for the first two parameters are generated in each individual time step based on the current value of $y_{t}$ using a truncated normal distribution quantile function (the inverse of the cumulative distribution function). Seedling mortality is defined to be the quantile function of $1-y_{t}$, resulting in increases in seedling mortality in "bad" years $\left(y_{t}<0.5\right)$ and decreases in "good" years $\left(y_{t}\right.$ $>0.5)$, whereas seed production is defined to be the quantile function of $y_{t}$, resulting in decreases in seed production in "bad" years $\left(y_{t}<0.5\right)$ and increases in "good" years $\left(y_{t}>0.5\right)$. Different values are used for the mean and standard deviation of the normal distributions used to generate seed production, seedling mortality, and postfire seedling mortality; these values do not vary over time (Table 1 ). This procedure results in values of seed production and seedling mortality 
being set at their mean in years when $y_{t}=0.5$. The third seasonally varying parameter $R$ (reproductive age) is nominally set at 9 years (Yates et al. 2003), but to simulate the effect of seasonal suitability on the initiation of seed production, a female tree only becomes reproductive in the first year in which it is 9 years or older and $y_{t} \geq 0.5$.

\section{Simulation of control measures}

We examined two methods of control based on strategies currently used in A. huegeliana management: fire alone and fire in combination with the mechanical removal of adult trees. Because of the inevitable presence of fire in the system, both wildfires and management fires for fuel load and heath regeneration purposes, we did not look at managed removal alone. Simulated fire is homogeneous across the patch because we were simulating a high-temperature intense management fire aimed at maximum A. huegeliana mortality (C. J. Yates, DEC, personal communication). Additionally, fire stimulates potentially massive seed bank germination in reseeder species such as A. huegeliana, which is simulated in the model by increasing seed germination in years of fire occurrence by a factor of 10 . The order within a single time step ensures that this can take place: the seed is produced and then mortality of adults occurs; fire does not cause seed mortality. Once the simulated patch is burned, it is considered bare of vegetation. In accordance with field findings (Yates et al. 2003, Maher 2007), the probability of individual seedling mortality is increased for any germinants in the first three years immediately postfire (Table 1).

For simulation of managed removal of A. huegeliana adults, trees that are "cut down" experience mortality and are removed from the simulation without the increased seed rain or harsher seedling environment. We assume some human error, so adult trees have a $90 \%$ chance of removal.

\section{Virtual experiments}

The parameterized model was used to conduct a series of virtual experiments. Kwongan patches are generally between 1 and 50 ha. For these simulations, the model was scaled to represent an area of 20.25 ha. There are generally existing stands of $A$. huegeliana adjacent to kwongan patches providing a continuous source of seed. These stands tend to occur in areas such as the base of granite outcrops that historically experienced less frequent fire than the kwongan due to higher moisture and lower dry fuel load (Morris 2000, Clarke 2002). To simulate this condition in our model, the bottom $10 \%$ of the landscape was designated as a fire refugium that did not burn during the model runs, thus creating a constant seed source of $A$. huegeliana into kwongan patches. The remaining upper $90 \%$ of the site represented the fireprone kwongan patch. This patch was initially empty of A. huegeliana and was subjected to a range of management strategies throughout the simulation.
Initialization consisted of the random placement of $100 \mathrm{~A}$. huegeliana individuals in the fire refugium. Because the model is stochastic, 50 fire cycles were simulated for each scenario.

We considered several different management regimes: regular fire occurrence, random fire occurrence, and regular fire occurrence in conjunction with managed removal. In the regular fire occurrence, we considered return intervals of between 20 and 80 years, in increments of 10 years. For the random pattern, fire occurred each year with a certain probability. We considered a range of probabilities corresponding to the same $20-80$ year range of return intervals considered for the regular pattern (i.e., $0.05 \leq p \leq 0.0125$ ).

Four management options of mechanical removal were considered, consisting of combinations of two different removal intervals and two different removal strategies. The first removal interval considered was based on $A$. huegeliana reproductive cycles: managed removal of adults occurred every 9 years. We also considered a longer removal interval of only once every 27 years, which would involve correspondingly lower effort and expense. We tested two removal strategies: removing all trees over the whole heath patch and removing only satellite populations. Many studies have shown that control of satellite populations, defined as small, incipient populations away from the original point of invasion, is a more effective tool against spreading invasion than controlling the original source (e.g., Taylor and Hastings 2004). Although we are assessing control on a relatively small scale $(<100$ ha), we were interested to see whether removing dense clumps of $A$. huegeliana in a heath patch (away from the invasive edge along the seed source) would decrease overall density through the reduction of concentrated, reproductive individuals. The strategy would be lower in cost and more easily implemented than whole-patch removal. We defined satellite populations as any $\sim 100$ $\mathrm{m}^{2}$ (or larger) area with $\geq 80 \%$ coverage by $A$. huegeliana. We then simulated the removal of all $A$. huegeliana individuals within the area covered by the satellite population.

The fires paired with mechanical removal were simulated over all fire return intervals in the regular occurrence pattern. Trees in the adjacent stand (the seed source) never underwent mechanical removal, as it is considered natural habitat for the species not appropriate for control measures.

\section{Analysis of results}

The purpose of this study is to advise which management choices will lead to the most efficient and effective control of the population and its impacts. In order to do so, we had to clearly define the relationship between the invasion and its impact. We used two different kinds of estimates. Primarily, we focused on the behavior of the invading population density and its response to management strategies. Additionally, we 


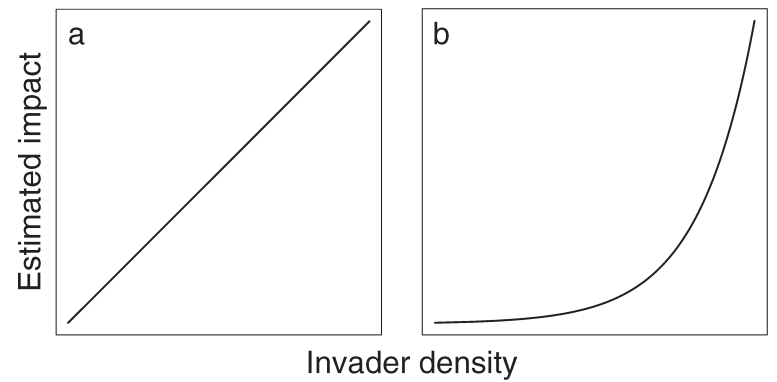

FIG. 2. Two estimated relationships of invasion density with its impact. (a) A linear relationship: as density increases, impact increases at the same rate. (b) A logarithmic relationship: as density increases, there is initially little increase in invader impact until a point at which there is a rapid increase in impact.

wanted to have an estimate of impact that was more directly ecological in its interpretation. We therefore used a very general estimate of impact to species richness through the species-area relationship, resulting in a logarithmic relationship between invader density and impact (Fig. 2).

Population response.-We used several measures to capture population behavior: the average rate of increase, where rate of increase is defined as $\lambda=N_{t+1} /$ $N_{t}$; maximum density reached under each management strategy; and average density after specific intervals since the last fire. For the average densities under the regular fire regimes, we averaged the patch density at the point just before the next fire over the 50 fire cycles included in each simulation (e.g., at years 20, 40, 60, and so forth for the 20-year return interval; years $30,60,90$, and so forth for the 30-year return interval; and so on). For the average densities under the random fire regimes, we chose the same times since last fire (20 years, 30 years, and so forth) and averaged the densities reached that many years after fire for those cases in which the period between fires was at least that long, ignoring those cases where another fire occurred before this period was reached. Average rates of increase were calculated over the same windows in the same way: for regular regimes we calculated rates of increase for each time step from one year after a fire up until the next fire and found the average; for random regimes, we only considered those fire cycles that were at least as long as the return interval under consideration, and averaged rates of increase for each time step over that period.

Estimated species richness impacts.- Species richness loss is an accessible and common way of measuring impact to a system. There are no specific rules for how an invasion will alter species richness, and no direct studies that we know of have been performed on A. huegeliana or a taxonomically related species to estimate its impact. Although controversial (e.g., He and Hubbell 2011), the species area-relationship is a commonly used estimate of species richness impact, and thus we chose to use it as a preliminary estimate of potential impact to biodiversity.
We consider its appropriateness as a measure of ecological impact in more detail in the Discussion.

We used data on species richness recorded by Brown and Hopkins (1983) in heath patches of different sizes to model species richness as a function of area according to the species-area relationship: $S=c A^{z}$, where $S$ is species richness, $A$ is area, $c$ is a constant, and $z$ is the rate at which species accumulate with increasing area (Connor and McCoy 1979). We found the predicted species richness of 1 ha to be $\sim 99$, with $c \sim 27.24$ and $z \sim 0.14$. As other species tend not to co-occur in the area occupied by $A$. huegeliana individuals, we assumed that each $A$. huegeliana individual reduced the area available for other species by the area of its occupied cell $(2.25 \times$ $2.25 \mathrm{~m}$ ). We then estimated impact as the reduction in species due to the maximum area occupied by $A$. huegeliana under a particular management scenario, based on our fitted species-area relationship. For species-area calculations, we considered the modeled heath patch to be one single contiguous area of habitat.

\section{Sensitivity analysis}

We conducted sensitivity analyses on parameters where their chosen value was uncertain. For all sensitivity analyses, we simulated a 30 - and 60 -year fire interval over 2000 time steps, and used average and maximum density as the output variable for analysis. We tested postfire mortality $\left(D_{\mathrm{f}}\right)$, the Cauchy dispersal scale parameter $(\gamma)$, the kernel distribution function, female probability $(F)$, and viable seed production $\left(s_{t}\right)$. Dispersal scale, female probability, and viable seed production were all tested at $\pm 50 \%$ of the model values, whereas postfire mortality was tested in $10 \%$ decreasing increments. We also assessed the sensitivity of the model to using different dispersal kernels with lower longdistance dispersal event occurrences (less leptokurtic or fat-tailed distributions): the Weibull distribution and lognormal functions. In order to enable direct comparison, parameters for these dispersal kernels were set such that the $98 \%$ quantile was the same as for the original Cauchy parameter values: in all cases, $98 \%$ of the seed fell within $45 \mathrm{~m}$ of the adult tree ( 20 cells). Additionally, we examined the effect of having fire in the seed source as well as the heath patch, by subjecting the refugium to fire over a range of intervals between 60 and 240 years in 60 -year increments. As stated, the model was built to have a constant, unburned seed source at the bottom of the simulated heath. However, it is likely that fire would historically occur in these patches infrequently, and we wanted to assess the impact that this occurrence would have on the model results.

\section{RESULTS}

\section{Model output}

Model outputs from example runs with a 60 -year fire return interval are given in Fig. 3. Note the decrease in density between fire with no removal (a) and fire with managed removal over the whole patch: (c) every 9 

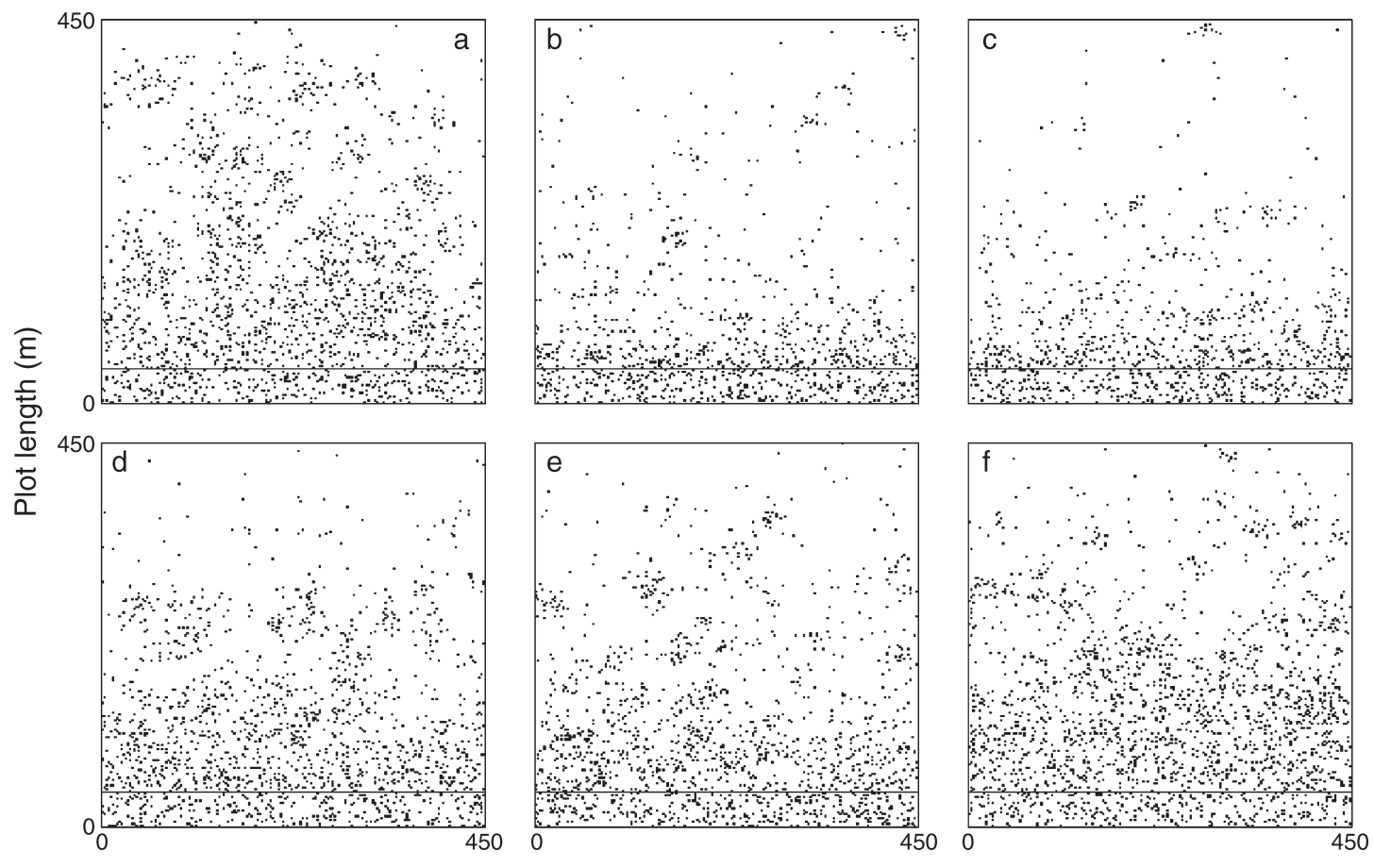

Plot width $(m)$

FIG. 3. Example output at 119 time steps after initiation for: (a) regular 60-year fire return interval (FRI); (b) random 60-year FRI; (c) regular 60-year FRI with mechanical removal over the whole patch every nine years; (d) regular 60-year FRI with mechanical removal over the whole patch every 27 years; (e) regular 60-year FRI with mechanical removal of satellite populations every nine years; and (f) regular 60 -year FRI with mechanical removal of satellite populations every 27 years. For each $450 \times 450 \mathrm{~m}$ plot, the area depicted, totaling 20.25 ha, is both the simulated fire refugium (lower $10 \%$ of area; below the black line) and heath patch (upper $90 \%$ of area), with white space being those cells unoccupied by $A$. huegeliana. Each black cell represents an $A$. huegeliana individual. Note that the depicted image of the random fire regime in panel (b) is only 14 years after the last fire, as opposed to the regular regimes, which are all 59 years after the last fire occurrence.

years; and (d) every 27 years. Small decreases can be seen in the management option of removing satellite populations (e) every 9 years; and (f) every 27 years. Also note that caution must be employed in comparing "snapshots" from single model runs such as these, due to stochastic variation; this is particularly the case for random fire regimes.

\section{Managed fire: regular and stochastic regimes}

We found that under all fixed fire return intervals, the population experienced only slow geometric growth; $\lambda$ fell between 1.1 and 1.3 for all fire return intervals simulated in the regular fire regime (Table 2). Although there was some evidence of slower increase as the return interval lengthened, even at 80 years since the last fire, there was no significant difference found in increase rates over fire-free periods, implying that that reductions in growth rates due to density dependence were not yet occurring. The return interval of the fire also made no difference in relative increase rates immediately postfire; at 20 years since the last fire, the increase rate under a 20 -year fire return interval was identical to that under an 80 -year fire return interval. The longer the time between fires, however, the higher the maximum densities reached in the heath patch (Fig. 4). Based on these maxima, the estimated impact on species richness consistently increased with the length of the fire return interval: at the shortest interval, estimated species loss reached only a maximum of 1 species/ha, whereas at the longest interval, it reached up to 6 species/ha (Table 3).

When the models were run with random burns, increase rates based on fire return interval and average densities at specific times since the last fire did not significantly differ from those under the regular regime (Table 2, Fig. 4). However, when long spans of time occurred without fire, the patch continued to experience increasing rates of invasion; thus the maximum density levels were higher under random regimes than regular regimes (Fig. 5). When fires occur at set intervals, the population has a cyclic behavior dependent on the return interval; when the fires occur probabilistically, there are long time spans with no fire. In these periods, the population reaches an apparent asymptote around 900 trees/ha. At such high densities, the richness impact is estimated to be around seven species lost per patch (Table 3). 
TABLE 2. Allocasuarina huegeliana rate of increase, $\lambda$ (mean $\pm 95 \% \mathrm{CI}$ ), for various fire return intervals (FRI): regular FRI; regular FRI with mechanical removal either over the whole patch every nine years, or removal of satellite populations every 27 years; and for random FRI.

\begin{tabular}{|c|c|c|c|c|c|c|c|c|c|c|}
\hline \multirow[b]{2}{*}{$\begin{array}{l}\text { FRI } \\
(\mathrm{yr})\end{array}$} & \multicolumn{2}{|c|}{ Regular } & \multicolumn{2}{|c|}{ Whole patch $9 \mathrm{yr}$} & \multicolumn{2}{|c|}{ Satellite $27 \mathrm{yr}$} & \multicolumn{4}{|c|}{ Random FRI } \\
\hline & $20 \mathrm{yr}$ & Max. yr & $20 \mathrm{yr}$ & Max. yr & $20 \mathrm{yr}$ & Max. yr & $20 \mathrm{yr}$ & Interval yr & Max. yr & $\begin{array}{l}\text { Max. time } \\
(\mathrm{yr})\end{array}$ \\
\hline 20 & $1.3 \pm 0.3$ & $1.3 \pm 0.3$ & $1.3 \pm 0.3$ & $1.3 \pm 0.3$ & $1.3 \pm 0.3$ & $1.3 \pm 0.3$ & $1.3 \pm 0.3$ & $1.3 \pm 0.3$ & $1.1 \pm 0.2$ & 84 \\
\hline 30 & $1.3 \pm 0.3$ & $1.2 \pm 0.3$ & $1.3 \pm 0.4$ & $1.3 \pm 0.3$ & $1.3 \pm 0.3$ & $1.2 \pm 0.3$ & $1.3 \pm 0.3$ & $1.2 \pm 0.2$ & $1.1 \pm 0.0$ & 142 \\
\hline 40 & $1.3 \pm 0.3$ & $1.2 \pm 0.2$ & $1.3 \pm 0.3$ & $1.2 \pm 0.2$ & $1.3 \pm 0.3$ & $1.2 \pm 0.2$ & $1.3 \pm 0.3$ & $1.2 \pm 0.2$ & $1.1 \pm 0.1$ & 152 \\
\hline 50 & $1.3 \pm 0.3$ & $1.1 \pm 0.2$ & $1.3 \pm 0.3$ & $1.1 \pm 0.2$ & $1.3 \pm 0.3$ & $1.1 \pm 0.2$ & $1.3 \pm 0.3$ & $1.1 \pm 0.2$ & $1.1 \pm 0.1$ & 172 \\
\hline 60 & $1.3 \pm 0.3$ & $1.1 \pm 0.2$ & $1.3 \pm 0.3$ & $1.1 \pm 0.2$ & $1.3 \pm 0.3$ & $1.1 \pm 0.2$ & $1.3 \pm 0.3$ & $1.1 \pm 0.2$ & $1.0 \pm 0.1$ & 213 \\
\hline 70 & $1.3 \pm 0.3$ & $1.1 \pm 0.2$ & $1.3 \pm 0.3$ & $1.1 \pm 0.2$ & $1.3 \pm 0.3$ & $1.1 \pm 0.2$ & $1.3 \pm 0.3$ & $1.1 \pm 0.2$ & $1.0 \pm 0.1$ & 403 \\
\hline 80 & $1.3 \pm 0.3$ & $1.1 \pm 0.2$ & $1.3 \pm 0.3$ & $1.1 \pm 0.2$ & $1.3 \pm 0.3$ & $1.1 \pm 0.2$ & $1.3 \pm 0.3$ & $1.1 \pm 0.1$ & $1.0 \pm 0.1$ & 491 \\
\hline
\end{tabular}

Notes: The two mid-effort mechanical removal regimes (whole patch $27 \mathrm{yr}$, satellite $9 \mathrm{yr}$ ) were excluded to simplify presentation. Averages were calculated (see Population response) over 20 years after fire in each scenario and over the maximum number of years after the fire for each regular scenario (20 years in the 20 -year return interval, 30 in the 30 -year, and so on). For the random return intervals, we calculated $\lambda$ with $95 \%$ CI over 20 years since the last fire, over the period until the expected average return interval, in cases where this interval was reached ("Interval yr" is 20 years after fire in the 20 -year FRI, 30 in the 30 -year, and so forth), and then over the single longest return interval found in each random scenario ("Max. yr").

\section{Managed fire and mechanical removal}

The additional benefits derived from mechanical removal were dependent on both fire regime and removal option. At shorter fire return intervals, when fires were occurring at intervals less than every $30-40$ years, mechanical removal at any level provided only small benefits. At 20- and 30-year fire return intervals, mean densities were not significantly different between management treatments. Maximum densities were within a $20 \%$ difference between no removal and full patch removal every nine years. Under all fire return intervals, increase rates were unaffected by mechanical removal (Table 2). At longer fire intervals, however, average and maximum densities were significantly reduced by all mechanical removal treatments (Fig. 4). At the highest removal of every nine years over the whole patch, average densities were significantly lower than all other treatments, and the maximum density reached under the longest fire return interval of once every 80 years was reduced by $71 \%$. That reduction was less under other shorter return intervals and other mechanical removal options. The two "moderate effort" removal strategies (removal over the whole patch every 27 years and removal of satellite populations every 9 years) resulted in population responses similar to each other regardless of fire return interval. No significant differences were found in mean densities (Fig. 4) or rates of increase. However, maximum densities were decreased by up to $24 \%$ under the higher frequency removal of satellite populations as opposed to the lower frequency removal over the whole patch.

The potential benefits of removal at longer fire return interval were emphasized in the estimates of species richness loss. When the fire interval was short or the removal effort was low, we found only small decreases in estimated species loss when mechanical removal was included (Table 3). For all fire return intervals, the lowest removal effort (satellite removal every 27 years) never decreased estimated species loss by more than one species. However at long return intervals or high removal efforts, estimated species loss was decreased by as much as $75 \%$. The largest decrease was found at a moderately long return interval (60 years) with the highest removal effort (removal over the whole patch every nine years). At this level of removal, no more than 2 species/ha were estimated to be lost under any fire return interval.

\section{Sensitivity analysis}

Varying postfire mortality had a dramatic impact on the population densities (Table 4).

At a 30-year fire return interval, average density quadrupled when mortality was reduced by only $10 \%$, from $100 \%$ to $90 \%$. At $70 \%$ mortality, average density was five times higher than at $100 \%$ and maximum density was more than double. At a 60 -year fire return interval, the average density more than doubled between $100 \%$ mortality and $70 \%$ mortality, whereas the maximum density was held fairly constant due to the already high maximum density of the 60-year return interval with $100 \%$ mortality.

When the patch was subjected to a 30-year fire return interval, removing the fire refugium resulted in population extinction if fires in the refugium were more frequent than once every 100 years. If fires in the refugium were less frequent than once every 100 years, the population was able to recover from fire through its own seed production; although average densities were reduced by up to half compared to simulations in which the refugium never burned, maximum densities across both were the same. Immediately after the refugium burned, populations were very low for a full fire cycle. This suppressed the average densities found at each time since last fire. However, after one fire cycle, the refugium had generally recovered and the subsequent fire cycles that occurred before the next fire in the refugium 

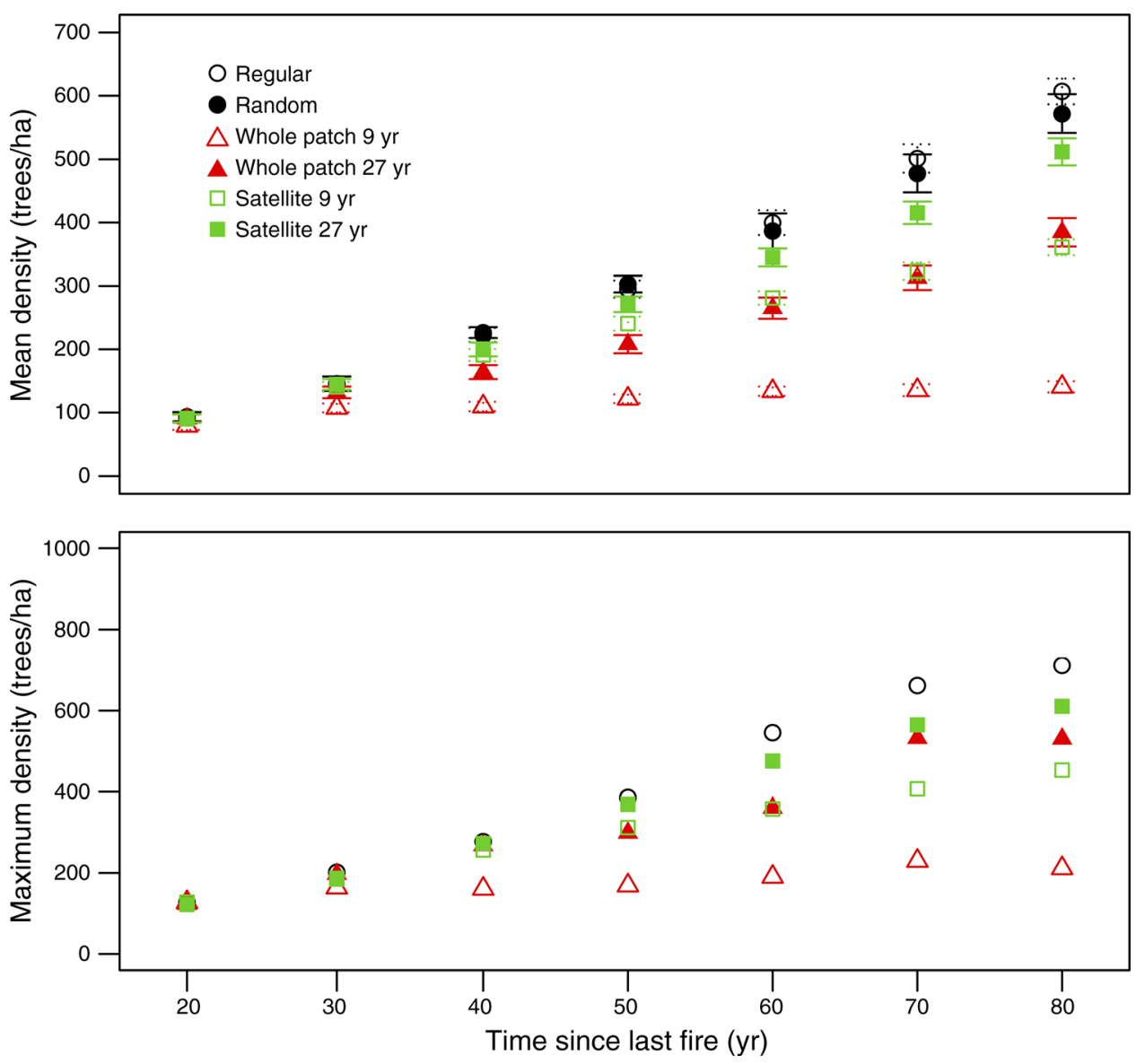

FIG. 4. Mean density just before fire in each return interval with $95 \%$ confidence intervals (top) and the maximum density reached within the 50 fire cycles (bottom) for: regular FRI; random FRI; regular FRI with mechanical removal over the whole patch every nine years; regular FRI with mechanical removal over the whole patch every 27 years; regular FRI with mechanical removal of satellite populations every nine years; and regular FRI with mechanical removal of satellite populations every 27 years. Note that the two $y$-axes have different ranges due to the maximum densities being higher than the average densities.

resulted in densities similar to those in the initial runs lacking any fire in the refugium. Under the 60-year fire return interval, removing the seed source by burning the refugium resulted in average densities similar to those under the 30-year fire return interval but higher maximum densities.
The functional form of the dispersal kernel was much more important than the value of the Cauchy function scale parameter, with the Cauchy kernel resulting in 3-4 times the average density and 2-4 times the maximum density when compared with results from the Weibull and lognormal kernels. Finally, varying the proportion

TABle 3. Maximum estimated number of species lost due to A. huegeliana density under fire return intervals of 20-80 years for regular FRI; random FRI; and regular FRI with mechanical removal over the whole patch every 9 and 27 years or regular FRI with mechanical removal of satellite populations every 9 and 27 years.

\begin{tabular}{ccccccc}
\hline \hline FRI (yr) & Regular & Random & $\begin{array}{c}\text { Whole patch } \\
9 \text { yr }\end{array}$ & $\begin{array}{c}\text { Whole patch } \\
27 \text { yr }\end{array}$ & $\begin{array}{c}\text { Satellite } \\
9 \text { yr }\end{array}$ & $\begin{array}{c}\text { Satellite } \\
27 \text { yr }\end{array}$ \\
\hline 20 & 1 & 3 & 1 & 1 & 1 & 1 \\
30 & 2 & 6 & 1 & 1 & 1 & 1 \\
40 & 3 & 6 & 1 & 2 & 2 & 2 \\
50 & 3 & 7 & 1 & 2 & 3 & 3 \\
60 & 4 & 7 & 1 & 3 & 3 & 3 \\
70 & 5 & 7 & 2 & 4 & 3 & 4 \\
80 & 6 & 7 & 2 & 4 & 3 & 5 \\
\hline
\end{tabular}




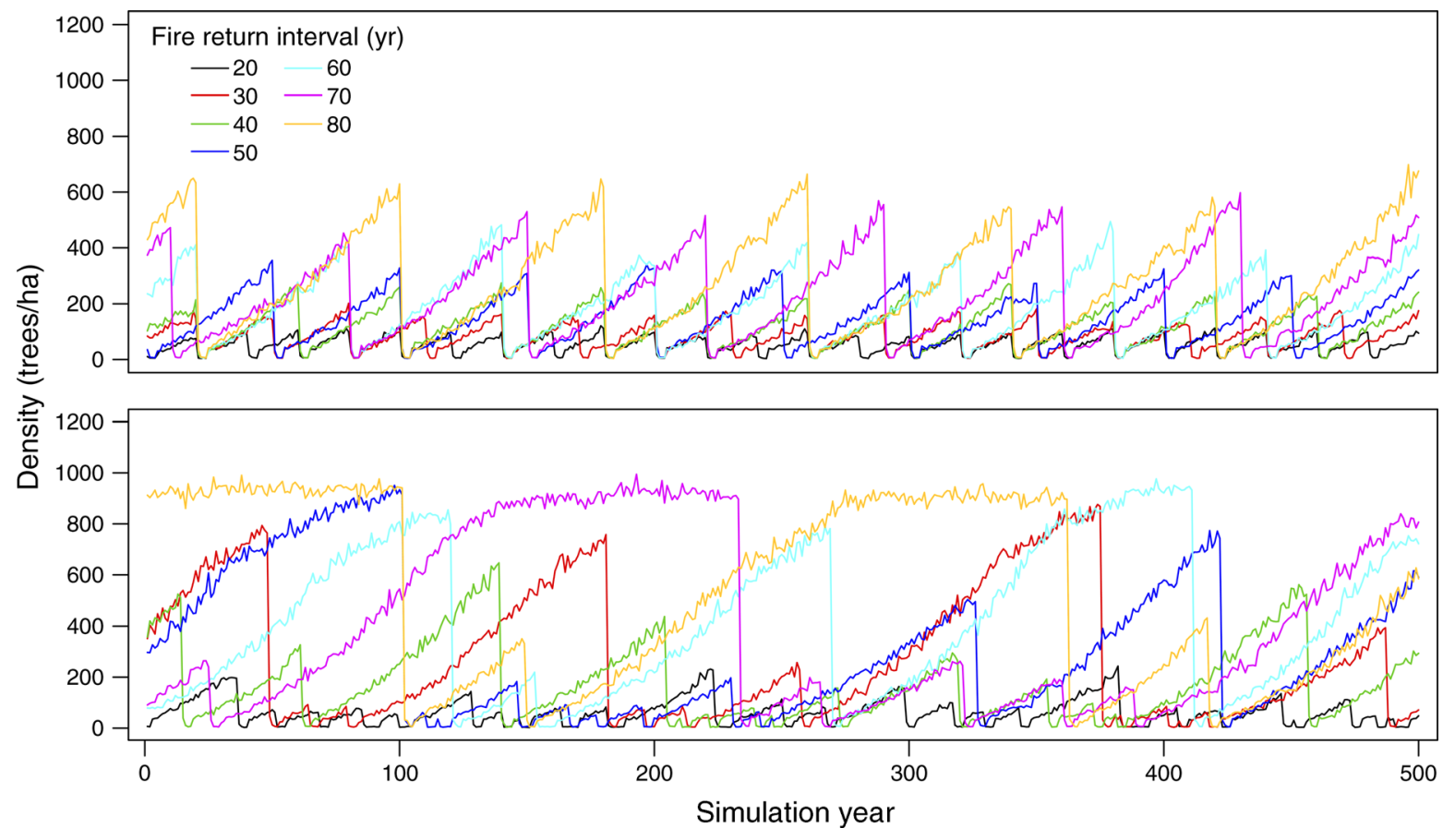

FIG. 5. Time series showing trees/ha over the last 500 years in particular example runs of each scenario with regular fire intervals, no mechanical removal (top), and random fire intervals (bottom). The $x$-axis shows the year within last 500 years of each simulation, and the $y$-axis is the patch population density.

of the population designated female had only a small affect on average and maximum densities.

\section{DisCUSSION}

Invasive species control is often required to maintain biodiversity in ecosystems (Mack and D'Antonio 1998). Managers are faced with choosing among multiple options for achieving optimal control, and simulation modeling can help to inform the decision of where and when to apply management. Using our preliminary estimate of impact to biodiversity based on fitted species-area curves and simulated $A$. huegeliana density, we found that $A$. huegeliana consistently began causing species loss after $\sim 30$ years without fire. At fire return intervals of 70-80 years between fires, incorporation of mechanical removal resulted in significant decreases in average $A$. huegeliana density over the patch. Interestingly, under a 60-year fire return interval, the maximum density reached under the regular fire regime was decreased by $55 \%$ under the most intensive removal effort (whole patch every 9 years), with a corresponding decrease in species impact estimated at $75 \%$ (from an estimated six species lost to two). This highlights the differences in interpretation of management efficacy based on the estimated relationship between the invasion and its impact. Although the difference here is not dramatic, it is plausible that impacts may be nonlinear and either disproportionately large or small at low invasive densities. The direction of nonlinearity defined here is that $A$. huegeliana will have little impact until it is in very high densities, due to the shape of the speciesarea relationship. However, the nonlinearity could operate in the opposite direction: low densities could have large impacts. Examples could include strongly allelopathic invasive species or species that disrupt ecosystem functions such as "magnet" species that alter plant-pollinator networks. These relationships are often unknown, as is the case in our ecosystem. However, the possibilities should be considered by managers when making species control decisions.

Current fire return intervals in heath patches are often 70 years or more and thus mechanical removal in areas where A. huegeliana invasion is a concern potentially could be worth the expense. As found in other studies (e.g., Taylor and Hastings 2004), there were clear benefits of removing trees over the whole patch rather than focusing on satellite populations. In small heath patches, removal over the whole patch is relatively straightforward. In larger patches, it becomes a question of resource availability vs. benefit. It is important to note that managed removal prior to fire potentially would also be worth the expense and effort required if mortality rates approaching $100 \%$ cannot be achieved during fire events; the model was extremely sensitive to postfire mortality levels. If fire return intervals were increased to every $30-40$ years and high fire mortality rates were achieved, mechanical removal at any level would give returns that were not a great improvement on fire alone. These results allow managers to make an 
TABLE 4. Results of the sensitivity analysis for each varied parameter for the 30 - and 60 -year fire return interval (FRI), presented as the average density (trees/ha) over the 2000-year runs and the maximum density (trees/ha) reached in the patch.

\begin{tabular}{|c|c|c|c|c|}
\hline \multirow[b]{2}{*}{ Parameter } & \multicolumn{2}{|c|}{ Density (trees/ha), 30-year FRI } & \multicolumn{2}{|c|}{ Density (trees/ha), 60-year FRI } \\
\hline & Average & Maximum & Average & Maximum \\
\hline \multicolumn{5}{|c|}{ Cauchy scale parameter, $\gamma$} \\
\hline$-50 \%: 0.625$ & 69 & 210 & 233 & 727 \\
\hline $0 \%: 1.25$ & 124 & 442 & 362 & 887 \\
\hline$+50 \%: 1.875$ & 167 & 519 & 437 & 951 \\
\hline \multicolumn{5}{|l|}{ Dispersal kernel } \\
\hline Weibull & 40 & 117 & 116 & 410 \\
\hline Cauchy & 122 & 437 & 362 & 890 \\
\hline Lognormal & 30 & 90 & 82 & 261 \\
\hline \multicolumn{5}{|c|}{ Female proportion, $F$} \\
\hline$-50 \%: 0.2$ & 95 & 271 & 275 & 808 \\
\hline $0 \%: 0.4$ & 120 & 381 & 362 & 899 \\
\hline$+50 \%: 0.6$ & 144 & 509 & 402 & 908 \\
\hline \multicolumn{5}{|c|}{ Seed production rate, $s_{t}$} \\
\hline$-50 \%: 75$ & 68 & 235 & 217 & 699 \\
\hline $0 \%: 150$ & 123 & 386 & 367 & 888 \\
\hline$+50 \%: 225$ & 173 & 535 & 438 & 934 \\
\hline \multicolumn{5}{|c|}{ Postfire mortality rate, $d_{t, \mathrm{f}}$} \\
\hline 1.0 & 123 & 426 & 361 & 894 \\
\hline$-10 \%: 0.9$ & 483 & 865 & 695 & 987 \\
\hline$-20 \%: 0.8$ & 582 & 938 & 728 & 973 \\
\hline$-30 \%: 0.7$ & 625 & 908 & 756 & 982 \\
\hline \multicolumn{5}{|c|}{ FRI in refugium (yr) } \\
\hline 60 & 4 & 251 & 2 & 99 \\
\hline 120 & 49 & 321 & $1 \overline{7}$ & 416 \\
\hline 180 & 74 & 381 & 73 & 553 \\
\hline 240 & 86 & 378 & 87 & 507 \\
\hline
\end{tabular}

Notes: In the first column, values that follow the colon are the parameter values at the different percentages. For example, the Cauchy scale parameter was set at 1.25 in the model presented throughout the paper. For the sensitivity analysis, we tested it at $50 \%$ of that value $(0.625)$, that value $(1.25)$, and at $150 \%$ of that value $(1.875)$.

informed cost-benefit analysis of different management options.

In our model, the regular fire regime resulted in constant fire intervals, whereas the random application of fire resulted in both short and long intervals without fire. We found very high maximum densities under the random regime, as well as high predicted species loss. This was due to the nature of random processes: in a 4000-year simulation (the length of time run for the 80year fire return interval), a century without fire was relatively likely to occur. Thus, the higher density and species loss results of the random runs were due to the model randomness, not specifically the behavior of $A$. huegeliana. The implication is that management goals cannot reliably be achieved through purely stochastic fire processes. However, it is important to note that fire, in reality, is not likely to be a purely stochastic event. It largely depends on climate, fuel loads, and ignition source, all of which might influence the probability of occurrence in a given year. A more complex model could take into account increasing or decreasing probabilities based on these factors. However, in agricultural areas such as the wheatbelt, land use change and human fire suppression would probably overwhelm the effect of many environmental variables and result in very low probability of a "stochastic" fire occurrence in a small, isolated reserve. This potentially could lead to some of the long fire-free intervals that occur in this model and thus to the high density and species loss results found here.

These long fire-free intervals result in higher reproductive populations and thus an increased seedling appearance immediately postfire. We hypothesized that this would lead to a more rapid coverage in postfire population spread, i.e., that rates of increase would differ between return intervals and between the regular and random regimes. We did not find this to be true. Although fire in the model first causes a dramatically increased fire-induced germination, the seedlings have very low survival and therefore the effects of the germination in repopulating the patch are overshadowed by the seed rain from the fire refugium. This causes the postfire population to effectively "start from scratch," so the rate of spread is not affected by previous long firefree intervals. Thus, fire return interval or having long periods without fire interspersed with short periods should not affect the speed of spread and establishment of $A$. huegeliana following a fire. Therefore, it appears 
that managers have flexibility in their timing of subsequent fires to control A. huegeliana. This simplifies management decisions, because the likely spread and establishment of $A$. huegeliana following fire should be similar, regardless of previous management history.

In applying a relatively large-scale disturbance such as fire over an entire heath patch, the system-wide impacts of the management choice need to be considered. Studies have shown in some heath systems that fire intervals longer than $\sim 45$ years can lead to structural senescence and heath degradation (Gosper et al. 2011). On the other hand, excessively rapid fire return intervals can lead to the loss of other fire-sensitive species important to the diversity of the heath system (e.g., McCarthy et al. 2001, Bradstock et al. 2006). Through the use of simulation modeling, Keith and Bradstock (1994) found that a fire cycle of short fire intervals intermixed with long fire intervals maintained the highest level of diversity within modeled heath patches. Therefore, an intermediate fire return interval that varies between 25 and 50 years would potentially maximize benefits to the system. According to our model results, a similar fire regime would likely prove effective at controlling the $A$. huegeliana population.

One final consideration for management is the type of fire used in $A$. huegeliana control. The simulated fire type would be novel relative to historical fires: the goal would be a hot, uniform fire to maximize A. huegeliana mortality, as opposed to the patchy fires of varying intensity that would have been the historical norm. Additionally, the density of $A$. huegeliana presence in the canopy might change both the strength and the behavior of the fire. The impacts of altered fire types to the system are not currently understood. Adaptive management would be required to respond to any adverse effects seen from the novel fire behavior. Mechanical removal options may allow for lower mortality or patchy fires while still controlling the population. Although modeling and scenario testing can potentially inform adaptive management such as this at each stage, monitoring and evaluation based on new data is essential. The strength of an adaptive strategy is that it allows for the unpredicted or currently unknown to inform future decisions.

As with all models, our model is an oversimplification of the many variables shaping the system and populations within it. In most instances, invasion is a complex process that co-occurs and interacts with several other factors that together cause environmental change. Kwongan in Western Australia is currently undergoing many environmental changes, including fire suppression, regional shifts toward an increasingly drier climate (Bates et al. 2008), and land use changes. A. huegeliana is a drought-tolerant species (Ladd 1989) that germinates reliable under a variety of conditions. These factors all could be synergistically contributing to both the invasion process and species decline. Although general management suggestions can be made from models such as ours, more precise management information could be obtained from a higher level of detail within the model that takes into consideration other environmental factors.

Additionally, we do not include data on the disturbance event itself such as fire intensity or season because there is no current information on whether these are pivotal factors in $A$. huegeliana population dynamics. In systems such as North American prairie, however, specific invaders require specific conditions in order for fire to be an effective management tool. For example, some alien herbaceous species may be better controlled by fires within the early growing season of the invader before viable seed production (DiTomaso et al. 2006, Simmons et al. 2007), whereas high fuel load is more important for control of invasive native woody species (Wink and Wright 1973). The modeling approach used in this study is general, in that it could be applied to the management of invasive species in other systems, but at the same time, can be tailored as required using details such as fire season and intensity to address specific management problems.

We have shown that control of a native invasive species is potentially achievable through disturbancebased management alone. However, this management tactic (the reinstatement of historic disturbance regimes or the application of novel regimes) could be effectively applied to nonnative invasion in certain contexts. Fire is a common example of altered disturbance and, as mentioned, has been used to control herbaceous species invasion in North American prairie. In arid stream and river habitats, the interruption of free-flow and natural flood regime has been a driver behind invasion by three Tamarix species (Stromberg et al. 2007), and the reinstatement of historic disturbance regimes in this system might be utilized for its control. Disturbancebased management may also be applied along with other control methods to manage novel systems, such as those with multiple invaders. In Australia, the herbaceous invader Verbena tenuisecta increased dramatically in response to the removal of the grassy invader Eragrostis curvula. However, when removal of Eragrostis was combined with ungulate grazing and nutrient addition, both novel disturbances to the system, the invasive herb was maintained at low levels (Firn et al. 2010).

Finally, of utmost concern in our model and in the management of invasive species is the clear definition of impact. In our model, one estimate of impact is area reduced by invader cover using the species-area curve. Recent research suggests that predictions of species loss based on the traditional species-area relationship may overestimate extinctions due to habitat loss ( $\mathrm{He}$ and Hubbell 2011). However, we believe that it is a relatively conservative estimate of invasive species impact, given that it is a process that does not involve direct habitat loss but rather area lost to a competitive species. In most cases of plant invasion, direct impact is difficult to quantify (Davis 2003) but involves interactions between 
the invader and surrounding species that go beyond mere spatial coverage. The impacts can arise from competitive interactions, exploitative or interference, and potential allelopathic behavior by the invader. In the particular case of $A$. huegeliana in heath, there are data showing much higher species loss in heavily invaded areas than would be predicted by the speciesarea relationship alone (N. Shackelford and M. P. Perring, unpublished data). Although achieving an exact quantification of invasion impact is unlikely, a clear definition with defined thresholds of effective or ineffective management is key to successful planning and implementation of management strategies.

Invasive species are, and will remain, a high conservation concern in coming decades (Vitousek et al. 1997). Management of invasive species will become increasingly sophisticated as we make full use of the tools available to us to make good decisions (Polasky et al. 2011). An advantage of simulation modeling is its ability to test the utility of different management scenarios over long time scales that is generally not possible with other approaches. In our case, we were able to predict the outcome of using fire for the management of a native invader, mimicking both historic and novel fire regimes. Having reasonable predictions means that managers have a basis of hypotheses to test with field experimentation and observational research, which can then be used to further improve the models. The continued development of simulation modeling in combination with other decision-making tools is likely to lead to improved ecological understanding of invaded systems and ultimately will advance our ability to manage invasive species in the coming decades.

\section{AcKnowledgments}

The data used in this paper were contributed by the Western Australian Department of Environment and Conservation Narrogin office. We thank the Ecological Restoration and Intervention Ecology Research Group, notably Rachel Standish and Kris Hulvey, for their comments and suggestions. We also gratefully acknowledge the helpful and insightful comments of an array of anonymous reviewers.

\section{Literature Cited}

Bamford, M. 1995. Exploring wheatbelt woodlands. Department of Conservation and Land Management, Perth, WA, Australia.

Bates, B. C., P. Hope, B. Ryan, I. Smith, and S. Charles. 2008. Key findings from the Indian Ocean Climate Initiative and their impact on policy development in Australia. Climatic Change 89:339-354.

Beecham, B., P. Lacey, and G. Durell. 2009. Conserving the biodiversity of the Tutanning Nature Reserve. Department of Environment and Conservation, Narrogin, Western Australia, Australia.

Bradstock, R., M. Bedward, and J. Cohn. 2006. The modelled effects of differing fire management strategies on the conifer Callitris verrucosa within semi-arid mallee vegetation in Australia. Journal of Applied Ecology 43:281-292.

Brown, J. M., and A. J. M. Hopkins. 1983. The Kwongan (sclerophyllous shrublands) of Tutanning Nature Reserve, Western-Australia. Australian Journal of Ecology 8:63-73.
Carey, M. P., B. L. Sanderson, K. A. Barnas, and J. D. Olden. 2012. Native invaders - challenges for science, management, policy, and society. Frontiers in Ecology and the Environment 10:373-381.

Clarke, P. J. 2002. Habitat islands in fire prone vegetation: do landscape features influence community composition? Journal of Biogeography 29:677-684.

Connor, E., and E. McCoy. 1979. The statistics and biology of the species-area relationship. American Naturalist 113:791833.

Davis, M. A. 2003. Biotic globalization: does competition from introduced species threaten biodiversity? BioScience 53:481489.

Davis, M. A. 2009. Invasion biology. Oxford University Press, New York, New York, USA.

de la Cretaz, A. L., and M. J. Kelty. 1999. Establishment and control of hay-scented fern: a native invasive species. Biological Invasions 1:223-236.

DiTomaso, J., M. Brooks, E. Allen, R. Minnich, P. Rice, and G. Kyser. 2006. Control of invasive weeds with prescribed burning. Weed Technology 20:535-548.

Firn, J., A. P. N. House, and Y. M. Buckley. 2010. Alternative states models provide an effective framework for invasive species control and restoration of native communities. Journal of Applied Ecology 47:96-105.

Fuhlendorf, S. D., F. E. Smeins, and W. E. Grant. 1996. Simulation of a fire-sensitive ecological threshold: A case study of Ashe juniper on the Edwards plateau of Texas, USA. Ecological Modelling 90:245-255.

Gosper, C. R., C. J. Yates, S. M. Prober, and B. C. Parsons. 2011. Contrasting changes in vegetation structure and diversity with time since fire in two Australian mediterranean-climate plant communities. Austral Ecology 37:164174.

He, F., and S. P. Hubbell. 2011. Species-area relationships always overestimate extinction rates from habitat loss. Nature 473:368-371.

Hierro, J. L., D. Villarreal, O. Eren, J. M. Graham, and R. M. Callaway. 2006. Disturbance facilitates invasion: The effects are stronger abroad than at home. American Naturalist 168:144-156.

Higgins, S. I., and D. M. Richardson. 1998. Pine invasions in the southern hemisphere: modelling interactions between organism, environment and disturbance. Plant Ecology 135:79-93.

Higgins, S. I., D. M. Richardson, and R. M. Cowling. 2000. Using a dynamic landscape model for planning the management of alien plant invasions. Ecological Applications 10:1833-1848.

Hobbs, R. 2000. Ecological repair following biotic invasions. Pages 181-188 in G. Preston, G. Brown, and E. Van Wyk, editors. Best management practices for preventing and controlling invasive alien species. The Working for Water Program, Kirstenbosch Botanical Gardens, Cape Town, South Africa.

Hobbs, R. J., and L. F. Huenneke. 1992. Disturbance, diversity, and invasion-implications for conservation. Conservation Biology 6:324-337.

Keith, D. A., and R. A. Bradstock. 1994. Fire and competition in Australian heath - a conceptual-model and field investigations. Journal of Vegetation Science 5:347-354.

Keith, D. A., L. Holman, S. Rodoreda, J. Lemmon, and M. Bedward. 2007. Plant functional types can predict decadescale changes in fire-prone vegetation. Journal of Ecology 95:1324-1337.

Keith, D. A., W. L. McCaw, and R. J. Whelan. 2002. Fire regimes in Australian heathlands and their effects on plants and animals. Cambridge University Press, Cambridge, UK.

Ladd, P. G. 1989. The status of Casuarinaceae in Australian forests. Pages 63-85 in First National Conference on 
Australian Forest History, Canberra, Australian Capital Territories, Australia.

Mack, M. C., and C. M. D'Antonio. 1998. Impacts of biological invasions on disturbance regimes. Trends in Ecology and Evolution 13:195-198.

Maher, K. 2007. Encroachment of sandpland heathland (kwongan) by Allocasuarina huegeliana in the Western Australian wheatbelt: the role of herbivores, fire and other factors. Murdoch University, Perth, Western Australia, Australia.

Maher, K. A., R. J. Hobbs, and C. J. Yates. 2010. Woody shrubs and herbivory influence tree encroachment in the sandplain heathlands of southwestern Australia. Journal of Applied Ecology 47:441-450.

Main, A. R. 1993. Landscape reintegration: problem definition. Pages 189-208 in R. J. Hobbs and D. A. Saunders, editors. Reintegrating fragmented ecosystems. Springer-Verlag, New York, New York, USA.

McCarthy, M., H. P. Possingham, and A. Gill. 2001. Using stochastic dynamic programming to determine optimal fire management for Banksia ornata. Journal of Applied Ecology 38:585-592.

Morris, K. 2000. The value of granite outcrops for mammal conservation in Western Australia. Journal of the Royal Society of Western Australia 83:169-172.

Parker, I. M., et al. 1999. Impact: toward a framework for understanding the ecological effects of invaders. Biological Invasions 1:3-19.

Pate, J. S., and J. S. Beard. 1984. Kwongan plant life of the sandplain. University of Western Australia Press, Nedlands, Western Australia, Australia.

Pausas, J. G., F. Lloret, and M. Vila. 2006. Simulating the effects of different disturbance regimes on Cortaderia selloana invasion. Biological Conservation 128:128-135.

Polasky, S., S. Carpenter, C. Folke, and B. Keeler. 2011. Decision-making under great uncertainty: environmental management in an era of global change. Trends in Ecology and Evolution 26:398-404.

Prober, S. M., and F. P. Smith. 2009. Enhancing biodiversity persistence in intensively used agricultural landscapes: A synthesis of 30 years of research in the Western Australian wheatbelt. Agriculture, Ecosystems and Environment 132:173-191.

Pyšek, P., and D. Richardson. 2010. Invasive species, environmental change and management, and health. Annual Review of Environment and Resources 35:25-55.

R Development Core Team. 2009. R: A language and environment for statistical computing. R Foundation for Statistical Computing, Vienna, Austria.

Ralphs, M. H. 2011. Broom snakeweed increase and dominance in big sagebrush communities. Natural Resources and Environmental Issues 17:8.
Shackelford, N., M. Renton, M. Perring, and R. Hobbs. 2011. Modeling invasion by Allocasuarina huegeliana in kwongan heathland and its management implications. Pages 25632569 in F. Chan, D. Marinova, and R. S. Anderssen, editors. MODSIM2011, 19th International Congress on Modelling and Simulation, December 2011. Modelling and Simulation Society of Australia and New Zealand, Perth, Australia.

Simberloff, D., L. Souza, M. A. Nuñez, M. N. Barrios-Garcia, and W. Bunn. 2011. The natives are restless, but not often and mostly when disturbed. Ecology 93:598-607.

Simmons, M. T., S. Windhager, P. Power, J. Lott, R. K. Lyons, and C. Schwope. 2007. Selective and non selective control of invasive plants: the short term effects of growing season prescribed fire, herbicide, and mowing in two Texas prairies. Restoration Ecology 15:662-669.

Standish, R. J., V. A. Cramer, S. L. Wild, and R. J. Hobbs. 2007. Seed dispersal and recruitment limitation are barriers to native recolonization of old-fields in western Australia. Journal of Applied Ecology 44:435-445.

Stromberg, J. C., S. J. Lite, R. Marler, C. Paradzick, P. B. Shafroth, D. Shorrock, J. M. White, and M. S. White. 2007. Altered stream-flow regimes and invasive plant species: the Tamarix case. Global Ecology and Biogeography 16:381393.

Taylor, C. M., and A. Hastings. 2004. Finding optimal control strategies for invasive species: a density-structured model for Spartina alterniflora. Journal of Applied Ecology 41:10491057.

Valéry, L., H. Fritz, J. C. Lefeuvre, and D. Simberloff. 2008. In search of a real definition of the biological invasion phenomenon itself. Biological Invasions 10:1345-1351.

Van Auken, O. 2009. Causes and consequences of woody plant encroachment into western North American grasslands. Journal of Environmental Management 90:2931-2942.

Vitousek, P. M., C. M. D’Antonio, L. L. Loope, M. Rejmanek, and R. Westbrooks. 1997. Introduced species: A significant component of human-caused global change. New Zealand Journal of Ecology 21:1-16.

Vitousek, P. M., C. M. D'Antonio, L. L. Loope, and R. Westbrooks. 1996. Biological invasions as global environmental change. American Scientist 84:468-478.

Whitford, W. G., R. Nielson, and A. de Soyza. 2001. Establishment and effects of establishment of creosotebush, Larrea tridentata, on a Chihuahuan Desert watershed. Journal of Arid Environments 47:1-10.

Wink, R. L., and H. A. Wright. 1973. Effects of fire on an Ashe juniper community. Journal of Range Management 26:326329.

Yates, C. J., S. D. Hopper, A. Brown, and S. van Leeuwen. 2003. Impact of two wildfires on endemic granite outcrop vegetation in Western Australia. Journal of Vegetation Science 14:185-194. 